\title{
Arte y sufrimiento: una posibilidad de transliterar en el arte
}

\author{
Art and suffering: a possibility to transliterate in art
}

\author{
Pablo Bruno Amato Mora ${ }^{1}$ \\ Sharon María González Herrera²
}

\section{RESUMEN}

En el presente artículo se desarrolla una investigación bibliográfica con el fin de destacar la relación existente entre el arte y el sufrimiento, siendo este último transliterado según la expresión del arte. Para esto, se realiza un recorrido biográfico de artistas como Frida Kahlo, Arthur Rimbaud, Pablo Picasso y Camille Claudel; a partir de ello fue que lograron darle forma, color y letra al propio dolor, externando lo que el cuerpo sentía, a manera de creación. Palabras claves: Arte, sufrimiento, Otro, transliteración, estética.

\begin{abstract}
The present article develops a bibliographical investigation in order to emphasize the existing relation between art and suffering, being the last one transliterated according to the expression of art. For this purpose, a biographical journey of artists including Frida Kahlo, Arthur Rimbaud, Pablo Picasso and Camille Claudel is carried out; on that basis, they were able to give form, color and letter to the pain itself, to show what the body felt, as way of creation.
\end{abstract}

Key Words: Art, suffering, Other, transliteration, aesthetic.

\footnotetext{
${ }^{1}$ Universidad de Costa Rica. Bachiller en psicología. Egresado de Licenciatura. Costa Rica. Correo electrónico: amato2187@ hotmail.com. Trabajo de investigación del Seminario de temas: La distintas escrituras del cuerpo: arte, estética y enfermedad (PS-1033) bajo la supervisión de la profesora Licda. Andrea Molina Ovares.

${ }^{2}$ Universidad de Costa Rica. Bachiller en psicología. Egresada de Licenciatura. Costa Rica. Correo electrónico: shar.mg13@ hotmail.com

Recepción: 1/5/2018 Aceptación: 26/6/2018.

(c) (†) () Compartirlgual 4.0 Internacional.
} 


\section{El sufrimiento tiene múltiples formas, una de ellas es el arte...}

El arte, como manera de expresión es considerado muchas veces un chivo expiatorio, y sus representantes, quienes se consideran los creadores de tales obras, cumplen con actuar con la función de ser los oficiantes de ese rito. Ser ellos mismos quienes prestan su propio cuerpo para llevar y cargar con el sacrifico de ser un paradigma: el artista sufridor.

Como antecedente histórico, cabe señalar al Agnus Dei, este cordero de dios, encarnado en la figura de Jesucristo, quien es sacrificado por un bien mayor, y expiar los pecados de la sociedad. Este tipo de arte perfomático, desde el punto de vista de Adell (2011) permite disimular la oportunidad de proyectar las frustraciones colectivas en los demás, fungiendo como un canal de escape para las irritaciones que genera. La sensación evocada es que, actualmente, se vive en una época en la que el dolor se ha catalogado con el fin de ser expuesto y museizado, para lo cual se construyen sin cesar altares al sufrimiento humano.

Caso puntual es el de Van Gogh en las cartas que le escribía a su hermano Theo, expresando la angustia retratada que padecía, y creía desde muy temprana edad que en cada generación siempre iban a existir dos o tres personas que se sacrificaran por los demás, descubriendo los dolores horribles que favorecían a los otros, creyendo al mismo tiempo que ese era su propio destino (Ruiz, 2016).

Debido a ello, es importante comprender que el propio cuerpo es representado por los artistas que pretenden trabajar su obra a través y, desde su propia prolongación carnal, que sirve como herramienta de investigación, de ensayo y error, como medio y como fin; ya que muchas veces la expresión de ese dolor en el cuerpo permite expresar y resignificar tal sufrimiento interno (ya sea psíquico o físico) junto con su representación externa (la creación); conjunción que simboliza un claro exponente en el dolor.

El cuerpo, explica Murillo (2010) es el diario de campo que registra los cambios con el paso del tiempo y lo hace evidente y explícito. No le gusta guardarse nada en los estantes del olvido. Queda claro que tiene la potestad de volverse cansino y agotador; se ama y se odia el mismo cuerpo, el mismo objeto, presenta las mismas características de ambivalencia porque simboliza todo lo bueno y lo malo del ser; pide a alguien que se ocupe de él, aunque sea Otro, o por medio de otra expresión. 


\section{Color, letra y forma del sufrir}

\section{Del dolor al color: hija de la época, servidora del arte, influencia de nadie; Frida Kahlo}

El arte como resultado del accidental encuentro entre una máquina de coser y una sombrilla encima de una mesa de disecciones (Fuentes, 1995).

Frida Kahlo estaba de acuerdo con la máxima planteada por Schopenhauer, aquella que decía "la vida es en esencia sufrimiento", ella lo había sufrido, lo experimentó de manera corpórea y, al mismo tiempo lo hizo arte. El filósofo alemán planteaba que el dolor tiene una dimensión empírica y un alcance objetivo, por lo que, las causas de ello eran capaces de ser identificadas como las fuentes de displacer, que podían ser suprimidas, logrando eliminar el dolor (Suarez, 2014). Desde muy joven a esta artista mexicana nacida en Coyoacán, hija de la Revolución -como a ella misma le gustaba autodenominarse- la vida le plantó cara y la muerte la retó. A los siete años contrajo poliomielitis con consecuencias importantes en una de sus extremidades inferiores y a los 18 años un tranvía chocó contra el autobús en el que ella viajaba (Armstrong, 2011).

La obra de Magdalena Carmen Frida Kahlo y Calderón representa un cuerpo que hace alusión tanto al dolor físico como el mental en cuanto a enfermedad y a su maternidad frustrada. Arte autobiográfico que narra las diferentes operaciones quirúrgicas, la pérdida, la turbulenta relación amorosa, y en determinado grado, el arte como una expresión de relato, una forma de pronunciar su ser sufriente, maltratado y desgarrado (Ruiz, 2016). Ella comienza con sus creaciones artísticas luego de ese casi mortal accidente de tránsito que le produjo la ruptura de la columna vertebral en tres lugares diferentes, fracturas de costilla, pelvis, clavícula, pierna derecha rota en diez pedazos y pie derecho aplastado. Un pasamanos del autobús se desprendió y atravesó su cuerpo, entrando por al abdomen y saliendo por la vagina. Razón por la cual queda postrada en la cama durante meses debatiéndose entre la vida y la muerte; hecho que marcaría en profundidad su existencia.

Perdí la virginidad, se me reblandeció el riñón, no podía orinar, y de lo que yo más me quejaba era de la columna vertebral. Nadie me hizo caso. Además, no se hacían radiografías. Me senté como pude y les dije a los de la Cruz Roja 
que llamaran a mi familia (...). Mi madre se quedó muda durante un mes por la impresión y no fue a verme. Mi hermana Adriana al saberlo se desmayó. A mi padre le causó tanta tristeza que se enfermó y solo pude verlo después de veinte días (Tibol, 2002, p.39).

En declaraciones posteriores expresaría que sus dos peores accidentes fueron aquel choque y el otro, Diego (Moreno, 2011). El cinco de diciembre de 1925, estando hospitalizada escribió: "Lo único bueno que tengo es que ya voy empezando a acostumbrarme a sufrir" (Tibol, 2002, p.43).

Mientras estuvo postrada sin poder moverse, la madre de Frida encargó un espejo que colgaron encima de su cama, por lo que lo primero que veía era siempre a sí misma, su imagen. Elemento clave en su obra, objeto determinante en sus autorretratos, situación que refleja en sus escritos (Ruiz, 2016).

¡El espejo! Verdugo de mis días, de mis noches. Imagen tan traumatizante como mis propios traumas. La impresión constante de que te señalan con el dedo. Frida mírate pues. Ya no hay una sombra verdadera donde esconderse, una guarida segura donde retirarse, abandonada al dolor, para llorar en silencio sin marcas en la piel. Imaginaba que cada lágrima creaba un surco en el rostro, aunque fuese joven y liso. Cada lágrima es una fragmentación de la vida (Rauda, 1994, p.123).

Para Kahlo, al igual que como en Séphora, el desgarramiento es lo que salva su propio arte, allí donde se enmarca la belleza con el dolor en una sola carne pero, ¿qué tipo de dolor? El que mencionaba Freud (1994) como dolor del duelo o dolor melancólico, dolor como el de la madre de Guernica abrazando a su hijo agonizante o como el de Van Gogh cortándose la oreja mientras seguía expectante contemplando el girasol con un sentido hipnótico o el de Picasso en tonos monocromáticos y desesperanzadores; en palabras de Nietzsche un "dolor perro", uno que se convirtió en ella por medio de un arte desvergonzado. Para Carlos Fuentes "su dolor no la vuelve muda, su grito es un aullido articulado porque alcanza una forma visible y emocional. Frida Kahlo es una de las grandes voces para el dolor en un siglo que ha conocido, acaso no más sufrimiento que otros tiempos" (Chen, 2008, p. 69) el cual le servía de medium para hacer patente la rasgadura de su existencia que gritaba de ira, de rabia, de incomprensión, y para no tener que estallar, pintaba, dibujaba o leía a Proust. "Su arte era la 
confidencia de un cuerpo doliente. En él resonaba lo más íntimo de lo humano: el sufrimiento" (Vásquez, 2016, p.124).

¿Cómo imaginarse ese peso con el que tuvo que cargar su cuerpo y el trauma psíquico generado -entre otras cosas- como consecuencia de ello? Sobreponiéndose a cuanta desdicha física se enfrentó y burlándose de la muerte a quien varias veces buscó verle los ojos tratando de suicidarse; logró vivir hasta los 47 años como una lisiada de guerra en sus últimos esfuerzos, desdoblándose a través de la escritura mediante un diario íntimo y continuando con la iconografía; creando un discurso escrito y pictórico a la vez, siendo uno de los grandes temas importantes ahí expuestos el de su "cuerpo enfermo y paulatinamente desgarrado, residencia de un espíritu que se rebela y lucha continuamente por mantenerse en el mundo, aunque la esperanza decaiga" (Armstrong, 2011, p. 58).

El amor por Diego Rivera también representó un obstáculo para ella misma, un vaivén de inestabilidad y desgarro del alma, un autosacrificio, un conjunto de binomios interpuestos: éxtasis y angustia, placer y dolor; un dolor tan grande como sus 22 cirugías realizadas entre 1910 y 1953. Frida el once de febrero de 1954 escribió en su diario:

Me amputaron la pierna hace seis meses, se me han hecho siglos de tortura y en momentos casi perdí la razón. Sigo teniendo ganas de suicidarme. Diego es el que me detiene por mi vanidad de creer que le puedo hacer falta. Él me lo ha dicho y yo lo creo. Pero nunca en la vida he sufrido más. Esperaré un tiempo... (Tibol, 2002, p.71).

A través de esas expresiones, queda la impresión que Frida ya no vivía para sí misma, incluso el reflejo de su pensamiento plasmado en las pinturas limitan aún más la evocación sobre ello. Entre ese escrito y el siguiente que aparece en marzo del mismo año, las hojas del diario han sido arrancadas, -según se relata- para mantener la dignidad de la autora debido a su intenso tormento. En esa etapa de la vida, Kahlo ya se encontraba familiarizada con la idea de la muerte, manifestando en una pintura de fondo amarillo su conocida frase: "Espero alegre la salida - y espero no volver jamás- FRIDA” (Armstrong, 2011, p. 70).

Finalizando sus días, los autorretratos estaban dirigidos hacia la desnudez propia atravesada por flechas, en los lugares donde ella localizaba el dolor y debilidad, espacios que la vida le recordaba físicamente sus heridas; mirada en alto, seria y con lágrimas en el rostro, producto de las batallas alcanzadas. 
No existen anotaciones que cierren las páginas de su diario íntimo, pero sí un último dibujo, muestra de su más preciada forma de expresión: una especie de tormenta celestial que esconde un sol, se cierne sobre la cabeza de un alado ser antropomorfo que convertido tal vez en alma, va dejando tras de sí, huellas de su propia sangre, el fin del dolor. (Armstrong, 2011, p. 71).

Frida Kahlo influenciada por su dolor y sufrimiento se dedicó a pintar y escribir su propia realidad, luchando incansablemente por librarse de esa carga. Siendo transgresora siempre a su manera. Ella fue historia, y la contó haciendo historia misma, con un lenguaje artístico.

\section{La literatura como crítica del sufrimiento humano: Arthur Rimbaud "Poeta maldito"}

El paraíso perdido es la transparencia perdida en el transcurso de la evolución de la humanidad, proceso en el cual el hombre se convirtió en el lobo del hombre (Castillejo, 2000, p. 148).

En una Francia donde florecía el neoliberalismo, de lógica mercantil y movimientos revolucionarios, crece un joven literario: Arthur Rimbaud (Castillejo, 2000). Caracterizado por su vida libertina pero a la vez marginal, un poeta que señala la importancia de aprender de sí mismo, de conocer sus verdaderos deseos; esto tiene un precio. A continuación, uno de sus primeros escritos, dirigido a Georges Izambard, de quien se detallará más adelante:

Quiero ser poeta y me estoy esforzando en hacerme Vidente: ni va usted a comprender nada, ni apenas si yo sabré expresárselo. Ello consiste en alcanzar lo desconocido por el desarreglo de todos los sentidos. Los padecimientos son enormes, pero hay que ser fuerte, que haber nacido poeta, y yo me he dado cuenta que soy poeta (Rimbaud, 2017, p.2).

A partir de sus escritos realiza críticas a la moral y costumbres de las personas de su época, concordando con Molina (s.f. a) quien señala que el sujeto crea un sello característico a partir de la creación propia, misma que identifica un vacío que da posibilidad a la existencia. Rimbaud escribe en poesía la existencia de una clase alta y una clase baja marcadamente distanciadas. Personas empobrecidas bajo el dominio de algunas adineradas; el poeta cuenta 
la historia que nadie más hace, amplia el panorama y señala una violencia legitimada. Su consciencia le motivaba a aliarse con los desposeídos.

¡Pero ahora ya lo sé! y mas no puedo creerlo: teniendo dos manos fuertes, conocimiento y un mazo, que pueda venir un hombre, la daga bajo su capa, y que me diga: ¡Villano, tú vas a sembrar mi tierra, y que venga, todavía, cuando ha estallado la guerra y, tal cual, coja a mi hijo y lo lleve de mi casa! —Yo, seré sólo un hombre, y tú, tú serás un rey, tú me dirás: ¡Eso quiero!... Ya lo ves, es algo absurdo ¿Crees que me agrada ver tu magnífica barraca, tus capitanes dorados, tus millares de bribones, tus ;sangre de Dios! bastardos, caminando como pavos: ellos llenaron tu nido del olor de nuestras mozas y de billetitos para mandarnos a las Bastillas. Nosotros diremos: Bueno, a los pobres ¡de rodillas! y doraremos tu Louvre soltando nuestro dinero, y tú te emborracharás y celebrarás la fiesta — ¡Y estos señores reirán, pisando nuestras cabezas! (Rimbaud, 2016, p. 206).

Realidad que vivencia dentro de su misma familia. Un padre que les deja cuando él tenía siete años de edad; criados por una madre exigente, preocupada por no mezclar a sus hijos con la clase obrera y que los mismos fueran del agrado de Dios (Vicent, 2010). Castillejo (2000) señala que en el poema Les Chercheuses des Poux de Rimbaud, se cuestiona la frialdad del vínculo entre el mundo del adulto y del niño, separados por una objetividad y exceso de razón de cada acción.

A partir de los 16 años de edad no regresa más a su casa. Inicia su travesía, huye un año después embriagado de amor con su maestro Georges Izambard (Vicent, 2010); relación caracterizada en un principio por admiración. Izambard reconoce sus cualidades y le motiva a iniciar una travesía aprendiz-maestro; con el pasar del tiempo Rimbaud deja de ser aprendiz, reta al propio mentor; es un Rimbaud interesado por lo desconocido. Junto a esto, una relación en donde el alcohol y las drogas no faltaron, ¿parte del poner a prueba a su propio ser? Para el final de su relación Izambard, en un ataque de celos le dispara en la mano, es encarcelado y sometido a investigaciones denigrantes para indagar sobre la homosexualidad.

Es en su juventud cuando Rimbaud cuestiona a la sociedad. No sólo en sus escritos transgrede, sino con la propia vida, sumergiéndose en vicios con drogas, alcohol y viviendo 
una sexualidad con un hombre. ¡Bastante intencional!, Rimbaud pretendía adentrarse a lo más profundo, lo que él consideraba el alma (Rimbaud, 2017).

Entra a una vida adulta y católica, él mismo se introduce al sistema mercantil, siendo la mayor paradoja de su vida. El poeta que le criticaba, está ahora de rodillas ante el neoliberalismo. Deja sus poemas y les clasifica como locura. Es un nuevo burgués, el que tanto odiaba el Rimbaud joven. Para Manzano (s.f.), en el poema "Tránsito" o "Partida" 3 se evidencian los primeros indicios de la despedida del mundo literario de parte de Rimbaud, más claramente visible en Adiós donde se señala lo relevante de la modernidad; ya él sabía sus propias limitaciones.

En esta etapa de su vida Arthur Rimbaud se comportó con la seriedad fiable de un perfecto burgués. Nada de escandalizar, ni de provocar, ni de saltarse las reglas. Era respetado por sus proveedores, pagaba las deudas en día de su vencimiento, saludaba con educación a sus vecinos, se quitaba el sombrero y besaba la mano de las damas (Vicent, 2010, párr. 8).

El sufrimiento estuvo presente en todos sus escritos. A partir de estos, muestra la decadencia del propio ser humano, sus abusos de poder y maldades diversas; Rimbaud lo experimenta en carne propia, es violado por un grupo de hombres del ejército. Se da la posibilidad en la literatura de demandar las crueldades que pasan por los ojos humanos, que por la habituación de la violencia y el moralismo no son cuestionadas.

Éstos son los conquistadores del mundo Buscando la fortuna química personal; El sport y el confort viajan con ellos; Llevan consigo la educación De las razas, de las clases y de los animales sobre este bajel Descanso y vértigo En la luz diluviana, En las terribles noches de estudio (Rimbaud, 2016, p. 164).

Pareciera que Rimbaud, piensa el arte como una experiencia que no logra encontrar en ningún otro lado, le daba esperanza. El arte le brinda una mirada, que ni la sociedad insaciable por la mercancía, ni sus Otros le ofrecen. Pero se está ante un poeta que se decepciona, renuncia a ese lugar encontrado; su vida es la propia obra, misma que se acaba al adentrarse

\footnotetext{
${ }^{3}$ Visto bastante. La visión se ha encontrado en todos los aires. Tenido bastante. Rumores de las ciudades, por la noche y al sol, y siempre. Conocido bastante. Los altos de la vida. — ¡Oh rumores y visiones! Partida hacia el afecto y el ruido nuevos (Rimbaud, 2016, p. 125).
} 
en la individualidad y modernidad que le posibilitaba la mercantilización de la persona, así es, Rimbaud también llega a ganar de la desgracia-esclavitud de otros ${ }^{4}$; a los pocos años muere.

Mas cuando este intento alucinatorio de la Cosa misma fracasó, Rimbaud cambió de vida al no poder cambiar la vida misma. Perdida la fe en el arte como remedio para la herida del existir, rehízo su camino como cualquier persona corriente convertido en mercader sin pasado alejándose cada vez más aprisa del horizonte donde el otro se derrumbó (Borer, 1993, párr.1).

\section{Retratos para un suicidio: la monocromía del azul; la tristeza de Picasso}

Al igual que el síntoma o la apariencia en la fenomenología de Heidegger, Sigmund Freud encontrará en "lo ominoso" (heimlich) -que también será traducido como "lo siniestro"-, aquel objeto familiar que esconde algo, donde la verdad se encuentra velada, y que al aparecer cambia de cualidad, convirtiéndose en algo terrorífico (Cattaneo, 2011, p. 4).

Quien fuera conocido como niño prodigio y nombrado Pablo Ruiz Picasso el 25 de octubre de 1881 fue capaz de “decir «lápiz» antes de poder ir a coger un lápiz él solo. Supo dibujar antes de hablar. Supo hablar antes de andar” (Bernadac y Bouchet, 2011, p.15).

Con el paso del tiempo, ese niño intelectualmente ávido, antojadizo de genio, ya convertido en adolescente conoce a Carles Casagemas en una taberna de Barcelona, llamada Els Quatre Gats (Los Cuatro Gatos) en 1899 y junto a Manuel Pallarès se vuelven amigos entrañables. Casagemas, bebedor sin fin, adicto a la morfina, con problemas de impotencia y poco agraciado, se enamora perdidamente de Germaine Gargallo a quien le pide matrimonio innumerable cantidad de veces, llegando a escribirle hasta dos cartas diarias con tal propósito, sin embargo, ella reniega de la propuesta (Godoy, 2013).

Cayendo el verano de 1900 -con sus últimos atardeceres- el célebre pintor a sus 19 años empieza a experimentar una fuerte necesidad de escapar, acuciantemente de ser él mismo y

\footnotetext{
${ }^{4}$ Castillejo (2000) menciona "Su marcha al África cierra, como dice Borer, la obra, pero también el sueño de changer la vie. Su vida allí es la de su sola individualidad inmersa en el mundo de las mercancías, su nuevo proyecto de vida" (p. 139).
} 
su voz artística (Bernadac y Bouchet, 2011) por lo que emprende viajes pendulares entre Barcelona, París y Madrid, donde se convierte en editor de la revista Arte Joven (Godoy, 2013).

Es el 17 de febrero de 1901 que frente al infructuoso ensayo de amor no correspondido por Germaine, Carles intenta -durante una cena de amigos- asesinarla, cuya muerte es impedida por el rápido accionar de Manuel, desviando el arma de fuego. Ese día cerca de las nueve de la noche, en L'Hippodrome Café, 128 Boulevard de Clichy, en París, Casagemas se suicidó mediante un balazo en la sien derecha, a los 20 años. Picasso se entera posteriormente de lo ocurrido, y mucho tiempo después le confiesa a uno de sus biógrafos, Pierre Daix, que pensar en la muerte de Casagemas lo llevó a pensar pintar en azul (Godoy, 2013).

Ese mismo año, cinco meses después de ocurrido el fatídico suceso, expresando el sufrimiento por la muerte de su íntimo amigo pinta de memoria su rostro, pálido, consecuencia de la defunción, junto a la luz de una vela que lo ilumina, con un estilo muy similar a las pinturas realizadas por Van Gogh (Bernadac y Bouchet, 2011).

Casagemas es Van Gogh inmolado en su pasión, así lo atestigua la coincidencia en sus destinos, así lo atestigua la manera de esta pintura con fuertes y gruesas pinceladas que hacen saltar los azules, rojos y negros con los amarillos de la luz de la vela, otorgándole al rostro del difunto un dramatismo sin igual; sin embargo hay un algo más terrible en esta pieza, otorgándole protagonismo, no a la muerte en sí, sino más bien al detalle por el cual esta acaeció: un "hoyo negro" a causa de la bala, una mancha brutal e ingrata pende sobre la sien derecha de Casagemas y vacía su figura (Godoy, 2013, p. 4).

No es sino hasta que encalla en Montmartre, en los conocidos años locos que inicia su "periodo azul" nombre heredado de los tonos predominantes y fríos de la gama cromática de sus pinturas, que se extiende durante cuatro abriles, de 1901 hasta 1904; época en la cual manifiesta su binomio indisoluble: Miseria y Creación. Según deposita en el papel su amigo Sabartés, Pablo “cree que el Arte es hijo de la Tristeza y del Dolor” (Bernadac y Bouchet, 2011, p. 26). 
Tal como lo expone Murillo (2010) al expulsar Dios al hombre y a la mujer del "santuario divino" los volvió en seres mortales, "terrestres" atrayendo con el castigo divino la aparición mortífera. Se aprendió, por dichas razones que todo tiene un tiempo de vida establecido, que existe la finitud. A partir de ahí se puede rastrear la existencia de la dualidad, como también los griegos, especialmente los filósofos y los médicos de la época hablaban sobre la dicotomía existente entre "mente-cuerpo"; algo que postuló el malagueño en sus trazos.

De ello hace un reflejo creativo la obra de Picasso; expresión de melancolía y pobreza que desarrolla, influenciado en pintores como El Greco, en cuanto a los detalles divisorios del espacio en dos partes, cielo y tierra, cuerpo y alma del "El entierro de Casagemas" o los ambientes bohemios, en donde aparecen principalmente personajes mendigos, borrachos, ciegos y prostitutas; una mirada que se dirige a los bajos fondos de la vida (Gil, 2014.). Con base en ello, Hounie (2016) denuncia que la vida más allá del placer se ve envuelta en una estética del dolor que acoge, abraza y sustenta la propia existencia, partiendo que en cada construcción artística existe en contraposición algo que también se pierde: "No existe una actitud establecida en relación con el dolor, sino una probable pero incierta, reveladora a veces de resistencias insospechadas, o a la inversa, de unas debilidades inesperadas, una actitud que también se modula según las circunstancias" (p. 4). Esas telas cargadas de monocromía le permiten al artista sobrellevar el duelo y la profunda tristeza que lo embriaga para exorcizar el espectro del suicidio, así como lo traumático de ello, el vacío que dejó tal marca de muerte.

Así como hizo con el ciclo de vida y muerte de su querido compañero: La muerte de Casagemas (1901) Casagemas en su ataúd (1901), Evocación, el entierro de Casagemas (1901) y La vida (1903) - uno de los lienzos más complejos de ese periodo- cargados con un simbolismo oscuro, logró representar en sus otras pinturas de esa época únicamente con el título, la potencia de la creación y destrucción en un mismo cuadro, como por ejemplo La tragedia (1903), El guitarrista ciego (1903), El asceta (1903), o La celestina (1904). En la primera cadencia que realiza el pintor se observa la fuerza que remite a ese espacio de la amistad y al vacío instaurado por la pérdida del vínculo. El segundo movimiento se verá encausado hacia el lugar que le otorga al deseo carnal, que se personifica en la figura de Gargallo a través de la relación amorosa que construye Pablo con ella, post-mortem Casagemas; intentando compensar lo que su amigo no consiguió, ese dolor que refleja en el 
querer incompleto y frustrado. El tercer movimiento de esta trama simbólica deviene en lo sagrado, ese espacio en el que cobra sentido -físico y psíquico- el vínculo con los muertos; hay que precisar, como señala Godoy (2013) que este malagueño prodigio

Será justamente desde la pintura y su capacidad taumatúrgica que Picasso hará del cadáver de su amigo un "cuerpo de trascendencia", en donde lo excepcional ritualice y a la vez sea ritualizado. A este respecto resultan clarificadoras las obras: Evocación, el entierro de Casagemas, en la cual Picasso le construye en el cielo un altar a su amigo muerto y La vida, en donde el pintor malagueño trae a la vida por última vez a su amigo, para despedirse de él (Godoy, 2013, p.10).

\section{Sufrimiento en la obra: Biografía de Camille Claudel contada en esculturas}

El arte más poderoso de la vida, es hacer del dolor un talismán que cura. ¡Una mariposa renace florecida en fiesta de colores! (Frida Kahlo).

Una sociedad, que se escandalizaba por un pensamiento de libertad, no muy distinto al existente en la actualidad, fue testigo de una mujer a quien el sufrimiento le acompañó hasta el final de sus días. Pareciera que el sufrimiento no tiene límites, no conoce las fronteras, y no deja de atormentar. Más interesante aun cuando se piensa en la posibilidad que brinda el arte para narrar una historia, vivencia, un "algo" que quizás de otra manera no sería apalabrado. Historia que Camille Claudel cuenta a partir de sus obras, una obra casi biográfica, misma que Arnoux (2001) relata a través de su libro, también como acto de enunciación, de demanda.

Se impondría una acción, quisiéramos poder señalar al, a los culpables, por lo menos a los responsables, o a quienes no hubieran hecho su trabajo y los que lo hubieran hecho en exceso. Y por qué no, en efecto, a los críticos de arte, al Estado, a Rodin, o bien a su hermano, o a sus padres (particularmente a la madre), a la psiquiatra, a la sociedad, al puritanismo, al diablo. Este libro habrá ido tomando, a cada paso, un partido desfasado (Arnoux, 2001, p. 19). 
Se podría pensar en el arte como una forma de marcar en la historia, de dejar su huella. Convoca a la existencia, a evidenciarla, da lugar al ser. Camille Claudel deja resto en la historia con su arte, en sus esculturas queda resto de su propio ser. En relación a esto, Molina (s.f. b) plantea:

Es como si la obra no solamente se encontrara narrando algo, sino que tiene la capacidad de arrancar algo de la realidad, y más aún de arrancarle algo a la creadora, un trozo de sí, lo que también podría verse como una caída de sí (p. $6)$.

Sus obras no solo evidencian parte de su vida, sino que atestiguan del sufrimiento. Son su única compañía. Le sostienen, tienen una razón de ser; estaba en un mundo que lo único que le ofreció fue el encarcelamiento y con ello la retirada de su sello, de su pronunciación. De esa retirada no queda más que la negación del sufrimiento propio; hay un Otro que gobierna el sufrimiento.

Para Camille sus obras son su huella del pasaje en esta vida. Son su manera de enunciar por su existencia; caracterizadas por efecto estético que permite "decir de lo imposible de decir" (Hounie, 2016, p. 174). Existencia que siempre estuvo en el poder de Otros. De su madre quien decide su destino de aislamiento, de su desaparición carnal; madre insensible a sus súplicas.

Me provoca toda la pena que es posible sentir verla tan desdichada (aunque seguramente exagera mucho) pero no puedo hacer más de lo que ya hago por ella, y si la soltaran de nuevo, toda la familia tendría que sufrir en lugar de una sola (Arnoux, 2001, p. 344).

Otro, su padre quien encomienda a su hijo Paul la responsabilidad de cuidar de Camille; su hermano Paul Claudel quien le toma como musa en sus poemas y a quien arrepentimiento le llega como ataques contra Rodin culpabilizándolo de la desgracia de su hermana, en algunos momentos como indiferencia ¿necesaria? y en otros, este arrepentimiento le llega muy tarde, esto cuando Camille es abandonada por completo en el asilo (Arnoux, 2001).

Massary, hermana quien le traiciona; Rodin a quien la misma Claudel le acusa de querer robar sus obras, de utilizarla como mujer, prometerle matrimonio y decirle muchas palabras que no pasaron a actos. Actos que solo son visibles en obras que atestiguan de su relación; es debido a ello que no es cualquier lugar el que juegan esas obras. De esto, Molina (s.f. a) 
aporta: "Es una contención que apunta directamente al cuerpo danzante o al cuerpo esculpido y que sostiene eso que se está diciendo más allá del mármol, más allá del movimiento” (p. 7). Por su parte, Arnoux (2001) enfatiza en esa relación-obra amor y odio: “Ahora bien, esta obra, en tanto que es realizada para un encargo del Estado, se convierte entonces como en una declaración oficial, vuelta pública, de su amor, ahora es ella el erastés, y una revelación de su odio" (p. 70).

Rose Beuret, por quien se forma esa triada en su relación con Rodin; de la sociedad imponente de normas morales que dejan una cuota estrecha al existente pero criticado albedrío; y del sistema de salud que se afanó por un diagnóstico y el encierro, ante un cuerpo, una mujer y una persona que lucha por ser deseada. Sin su obra, Camille Claudel dejaba de ser, le necesitaba. Arnoux (2001) cuestiona “ ¿fabrica la propia Camille Claudel su vida como una novela?” (p. 32) y más adelante su hermano, Paul Claudel relata una existencia a partir de su arte. Espacio que le da libertad de ser, de creación, de relato; espacio que sí gobierna.

De todo esto, ¿acaso no hay vida sin sufrimiento?

Así quedó establecido en aquella frase de El mundo que dicta de una vez por todas la sentencia sobre todo lo viviente: «Todo querer nace de la necesidad, o sea, de la carencia, es decir, del sufrimiento». Si querer supone sufrir, y si nada hay que pueda aplacar el ansia de la voluntad porque nada existe fuera de ella, la consecuencia es clara: la voluntad está por naturaleza condenada al sufrimiento eterno. El dolor no es, pues, un accidente de la vida sino su elemento consustancial. Porque nuestra esencia es querer, la nuestra es una vida de dolorosa necesidad que solo encontrará algunos momentos de tregua para entregarnos en manos del aburrimiento (Schopenhauer, 2009, p. 19).

Schopenhauer sugiere una vida determinada al sufrimiento. Vida y sufrimiento son casi la misma cosa, se nace para sufrir, en palabras de Hounie (2016) "habita lo humano" (p. 172) y de ahí que forme parte del mismo lenguaje. Sin embargo, dependiendo de la posición en que se encuentra ese ser, así será la dimensión de su sufrimiento. Se podría pensar en el artista como genio, tal y como lo señala Arnoux (2001), un genio que debe pagar tal cualidad; es una maldición que no cualquiera resiste, "tenemos al alcance de la mano una versión romántica y feminista: "artista maldita" es casi un pleonasmo. Mujer y rebelde, al crear una obra genial. Camille Claudel habría sido víctima de una maldición. El genio se paga (...)” 
(Arnoux, 2001, p. 18). En relación a lo anterior, se plantea que no sólo el vivir genera sufrimiento, sino también el no vivir. ¿A qué se hace mención? Una pérdida de un deseado hijo, un aborto que es cargado en la consciencia debido al señalamiento constante de las miradas conocidas y desconocidas. Un aborto, un no nacido que conmueve y aunque sus ojos nunca fueron vistos sí fueron llamados, convocados.

\section{Algunas conclusiones}

Frida Kahlo, Arthur Rimbaud, Pablo Picasso y Camille Claudel hicieron de su arte una posibilidad para transliterar el sufrimiento y quizás resignificarlo. La creación artística se convierte en un medio para expresar vivencias, permitiendo guardar memoria de las experiencias que han hecho signo en la persona. Se está ante la posibilidad de una manera de expresión diferente, alternativa.

Cabe preguntarse verdaderamente ¿el sufrimiento es reducible a una expresión, como es el arte?, ¿cuánta representación tiene de parte objetiva y racional? Sin duda, la obra representa la subjetividad impuesta y completa de quien la realiza; se consigue un valor único, pero también referencial que transmite un momento determinado, bajo una lupa que detalla aspectos íntimos, que mimetizan las vivencias idiosincráticas poseedoras de una vedad no absoluta, pero increíblemente liberadora para quien la imagina, le da forma y logra concebirla. Va más allá de domesticar el sentimiento, de reconocerlo. Es hacerlo consciente, trabajar con ello, visibilizarlo y nombrarlo. Aceptar que se puede crear a partir de él y construir. Es decir, existe una utilidad, sin embargo, la capacidad de concretarla de tal manera ocurre en y por la obra.

De estas obras artísticas nos preguntamos ¿hasta qué punto relataban parte de una vida o estas obras eran la vida propia del artista? Cuesta separar, dividir a la persona-artista de su creación, ya que sus vidas están plasmadas allí mismo, se han convertido en su diario íntimo, es la escritura biográfica a partir del lápiz, la pintura o el cincel. Se torna imposible hablar de uno sin lo otro.

Son muchos los rastros a través de la historia que dictan la relación entre el sufrimiento, el dolor y el arte. No se discute ya si se considera una musa, una inspiración. Al contrario, se busca externalizarla, trasladarla hacia un objeto que sea capaz de arropar tal estado anímico. 
Estas personas-artistas han encontrado en sus manos, una posibilidad de dar vida a algo más. Han utilizado su cuerpo como medio de creación. Es el arte el espacio que han encontrado para tener el control de lo que Otros le niegan, le tratan de callar. Es estética. No hay sedación del ser, permite construir, de-construir, debatir, enunciar, demandar. Es el pasar una escritura que puede ser llamada sufrimiento: en el cuerpo, en lo psi y dar vida a una obra.

\section{Bibliografía}

Adell, A. (2011). El arte como expiación. Madrid: Casimiro.

Armstrong, P. (2011). El diario íntimo de Frida Kahlo: amor y transgresión. Tesis para optar por el grado de maestría en Literatura con mención en Literatura Hispanoamericana y Chilena. Universidad de Chile, Santiago de Chile, Chile. Recuperado de http://www.repositorio.uchile.cl/handle/2250/108739

Arnoux, D. (2001). Camille Claudel. El irónico sacrificio. México D.F, México: Editorial Psicoanalítica de la Letra.

Bernadac, M y Bouchet, P. (2011). Picasso genialidad en el arte. Barcelona: Blume.

Borer, A. (3 de enero de 1993). Rimbaud en abisinia. El tiempo. Recuperado de http://www.eltiempo.com/archivo/documento/MAM-4758

Carré, J. (1954). Vida de Rimbaud. Recuperado de http://www.mercaba.org/SANLUIS/ALiteratura/Estudios/Carre,\%20Jean\%20Marie \%20-\%20Vida\%20De\%20Rimbaud.pdf

Castillejo, J. (2000). Arthur Rimbaud y la modernidad. Suma Cultural, 1, 107-154. Recuperado de http://www.konradlorenz.edu.co/images/stories/suma_cultural/20001/artthur.pdf

Chen, L. (2008). Frida Kahlo: vida y trabajo. Observatorio Laboral Revista Venezolana, 1(1). 
Freud, S. (1994). Obras completas. Duelo y meláncolía (vol XIV Amorrortu). Amorrortu Editores. Buenos Aires, Argentina.

Gil, J. (2014). Picasso, de la realidad a los sueños. III jornada de aprender investigando. Universidad de Sevilla, España. Recuperado de http://institucional.us.es/aulaexp/PanelP/PICASSO.pdf

Godoy, I. (2013). Suicidio en azul con negra mancha. Breve historia de un balazo en la pintura de Pablo Picasso. Arbor, 189(764), 087. Recuperado de http://arbor.revistas.csic.es/index.php/arbor/article/view/1889/2084

Hounie, A. (2016). El dolor tiene muchas caras. La subjetividad comprometida: fragmentos de una estética del dolor. En Fernández, A. y Hounie, A. (Coord.). Políticas del dolor. La subjetividad comprometida. Un abordaje interdisciplinario de la problemática del dolor (pp. 170-178). Uruguay: Ediciones Universitarias.

Manzano, J. (s.f.). Rimbaud o el malditismo. Recuperado de http://www.tindon.org/julia_manzano/poesia10.pdf

Molina, A. (s.f.a). Danza, cuerpo y escritura. (Artículo sin publicar). Universidad de Costa Rica, San José, Costa Rica.

Molina, A. (s.f.b). Locura y creación: más allá del mármol, más allá del movimiento. (Artículo sin publicar). Universidad de Costa Rica, San José, Costa Rica.

Moreno, A. (2011). Frida Kahlo. Viva la vida. España: Difusión.

Murillo, M.R. (2010) La efectuación del estrago materno en la constitución de la feminidad: de lo psicosomático a la escritura. Una lectura psicoanalítica de la novela Las palabras para decirlo de Marie Cardinal. Tesis para optar por el grado de Maestría en Psicología, UCR, San José, Costa Rica.

Rauda, J. (1994). Frida Kahlo. Barcelona: Circe.

Rimbaud, A. (2010). Cartas del vidente. Buenos Aires, Argentina: Editorial del cardo. Recuperado de http://www.biblioteca.org.ar/libros/153514.pdf 
Rimbaud, A. (2016). Arthur Rimbaud. Obra completa, Prosa y poesía. España: Ediciones 29. Recuperado de https://somoslxspiratas.files.wordpress.com/2016/07/obracompleta-prosa-y-poesia-de-arthur-rimbaud.pdf

Ruiz, I. (2016). El autorretrato como canalizador del dolor. Tesis Doctoral. Universidad de Granada.

Schopenhauer, A. (2009). Parerga y Paralipómena II. España: Editorial Trotta. Recuperado https://redpaemigra.weebly.com/uploads/4/9/3/9/49391489/parerga_y_paralip\%C3 \%B3mena_ii_-_schopenhauer_arthur.pdf

Suárez, L. (2014). La analítica del sufrimiento humano en Schopenhauer. Pensamiento. Revista de Investigación e Información Filosófica, 70(264), 475-494.

Tibol, R. (2002). Frida Kahlo: una vida abierta. México: Diversa.

Vásquez, M. (2016). Frida Kahlo Entre el sufrimiento y el arte. Revista de Filosofía, 81(3).

Vicent, M. (28 de agosto de 2010). Arthur Rimbaud: Yo es otro. El país. Recuperado de https://elpais.com/diario/2010/08/28/babelia/1282954362_850215.html 